\title{
Screening for dry eye disease using infrared ocular thermography
}

DOI:

10.1016/j.clae.2016.08.004

\section{Document Version}

Accepted author manuscript

Link to publication record in Manchester Research Explorer

\section{Citation for published version (APA):}

Tan, L. L., Sanjay, S., \& Morgan, P. B. (2016). Screening for dry eye disease using infrared ocular thermography. Contact Lens and Anterior Eye, 39(6), 442-449. https://doi.org/10.1016/j.clae.2016.08.004

\section{Published in:}

Contact Lens and Anterior Eye

\section{Citing this paper}

Please note that where the full-text provided on Manchester Research Explorer is the Author Accepted Manuscript or Proof version this may differ from the final Published version. If citing, it is advised that you check and use the publisher's definitive version.

\section{General rights}

Copyright and moral rights for the publications made accessible in the Research Explorer are retained by the authors and/or other copyright owners and it is a condition of accessing publications that users recognise and abide by the legal requirements associated with these rights.

\section{Takedown policy}

If you believe that this document breaches copyright please refer to the University of Manchester's Takedown Procedures [http://man.ac.uk/04Y6Bo] or contact uml.scholarlycommunications@manchester.ac.uk providing relevant details, so we can investigate your claim.

\section{OPEN ACCESS}




\section{Screening for dry eye disease using infrared ocular thermography}

Li Li Tan* MMedSc (Optom), BOptom (Hons), FAMO, FIACLE

Srinivasan Sanjay ${ }^{\S}$ MBBS, MRCS(Edin), MMed(Oph)(Sing), MS(Oph), DNB(Oph)

Philip B. Morgan ${ }^{\dagger}$ PhD, MCOptom, FAAO, FBCLA

*School of Chemical and Life Sciences, Singapore Polytechnic, Singapore

$\S$ Ophthalmology and Visual Sciences, Khoo Teck Puat Hospital, Singapore

$\S$ Yong Loo Lin School of Medicine, National University of Singapore, Singapore

${ }^{\dagger}$ Eurolens Research, The University of Manchester, UK

Correspondence to:

Li Li Tan

500 Dover Road

School of Chemical and Life Sciences

Singapore Polytechnic

Singapore 139651

Fax: (65) 68704617

tanlili@sp.edu.sg

Number of tables: 4

Number of figures: 5 


\section{Introduction}

2 Dry eye disease (DED) is a commonly encountered condition in clinical practice and affects up to

$312.3 \%$ of the population in Singapore [1] with a world prevalence range of $5 \%$ to $38 \%$ [2]. The

4 condition has remarkably impact on daily social and physical functioning, work place productivity

5 and quality-of-life [3-6]. Diagnosing the disease can be a tedious and challenging task [7] and been

6 hampered by the lack of objective tests with sufficient sensitivity and specificity, adequate

7 repeatability, ease of performance, and suitability for the clinical practice setting particularly in early

8 or mild cases [8]. Due to its multifactorial nature, DED potentially requires a broad spectrum of test

9 measures in the monitoring of its diagnosis and treatment [9]. While there are many clinical tests

10 for DED, the diagnostic values can be inconclusive [10-11] and may not be repeatable and/or

11 reliable because of variable results, poor reproducibility and low sensitivity [12-15]. Determining the cause of dry eye when minimal clinical signs are present is difficult and the diagnosis is complicated further when there is a lack of correlation between its signs and symptoms [11,16-22].

Tear film stability is a key test in screening and diagnosing DED [8]. It has been reported that capturing ocular surface temperature (OST) changes using infrared (IR) ocular thermography reflects the nature of the tear film [23-24] and its stability [25] and can be used to screen DED [26, 27]. However, temperature metrics available from ocular thermography to screen DED were limited and remain unclear. Most studies on OST and dry eye have evaluated the temperature of the geometric center of the cornea $[23,26,28-30]$. A small number of studies evaluated other metrics such as the relative differences in temperature across the ocular surface [31,32], mean ocular surface temperature [32,33], temperature at the nasal and temporal conjunctiva [26] and temperature difference and compactness values of the OST [27]. Two reports on dry eye screening using ocular thermography were done using temperature of the geometric center of the cornea [26] and temperature difference and compactness values of the OST [27].

The current study was devised to evaluate the efficacy of IR ocular thermography as a diagnostic tool for DED and to determine the most effective temperature metrics, applied singly or in combination.

\section{$31 \quad$ Methods}

\section{Subjects}

33 The research protocol was approved by the Singapore National Health Group (NHG) Domain34 Specific Review Board (DSRB) and the Singapore Polytechnic ethics review committee and the work adhered to the tenets of the Declaration of Helsinki. Informed consent was obtained from each subject at study enrolment. Sixty-two dry eye (48 \pm 10 years; 14 Male and 48 Female) and 63 age- and sex-matched control subjects ( $46 \pm 7$ years; 16 Male and 47 Female) completed the study

39 They were classified based upon a composite disease severity index, derived from the Dry Eye 40 Workshop severity scale [34]. The inclusion criteria for the dry eye subjects were as described 
41 previously [35]: use of tear replacement therapy and had either a fluorescein tear break-up time of 4210 seconds or less [36], or a Schirmer I test result of less than $10 \mathrm{~mm}$ in $5 \mathrm{~min}$ [31] along with 43 presence of corneal or conjunctiva staining. All dry eye patients were screened and diagnosed by 44 an ophthalmologist at Khoo Tech Puat Hospital eye clinic. Control subjects were those not using 45 tear replacement therapy or any topical medication and without signs or symptoms of dry eye. All 46 subjects were required to be noncontact lens wearers for at least two years prior to enrolment.

47 Subjects were excluded from control group if they had Schirmer I test result of less than $10 \mathrm{~mm}$ in 5 48 min or fluorescein tear break-up time of 10 seconds or less. Subjects with any anterior ocular 49 anomalies (e.g. current ocular infection, allergy or ptosis), those undergone surgery or taking any 50 medication that could affect the tear film or who were currently pregnant or breastfeeding were also 51 excluded.

\section{Procedures}

54 The procedures were the same as described previously [35]. Subjects were asked to refrain from 55 56 using their eye-drops or eye make-up on the day of measurement. Ocular thermography was performed in real time using an Infrared thermo-tracer (NEC TH9420) with resolution of $640(\mathrm{H}) \mathrm{x}$ $480(\mathrm{~V})$ pixels, operational sensitivity of $0.06^{\circ} \mathrm{C}$ and frequency of 30 frames per second, detecting infrared radiation between 8 and $14 \mu \mathrm{m}$. The emissivity of 0.98 was assumed [37]. A standard examination protocol as reported in the literatures $[23,25,26,32]$ was adopted. All the measurements were performed from $9 \mathrm{am}$ to $2 \mathrm{pm}$ in the same room with controlled room temperature $\left(24.06 \pm 0.41{ }^{\circ} \mathrm{C}\right)$ and humidity $(49.76 \pm 2.61 \%)$, with no air drifts and same brightness (380 lux). Subjects were adapted to the room for 20 minutes prior to ocular thermography as previous work has shown that this period was necessary to achieve ocular temperature stabilisation [38]. OST was recorded under the conditions described by Morgan and associates: the subjects blinked normally, closed for $3 \mathrm{~s}$ and the first image was recorded just after the eyes had opened [32,39]. $0 \mathrm{~s}$ was recorded as the time upon eye opening. 300 frames of real time thermal images reflecting OST changes at the ocular surface were captured over $10 \mathrm{~s}$ sustained eye opening. The measurement was done three times on right eye followed by left eye. At any time if subject blinked or changed fixation before $10 \mathrm{~s}$, the measurement was discounted and repeated.

A novel 'diamond' method was used to mark the ocular surface using a custom-designed OST Analysis V2 software (developed using MatLab Simulink 7.11.0, R2010b). The region of interest (ROI) formed by five anatomical points (labelled as 1 - 5) shaped like a diamond (Fig. 1). This method has the advantages of (1) overcome problems of truncated image by upper lids [40] and (2) minimize possible inconsistency in OST acquisition due to variation in palpebral aperture size and (3) enable study of the inferior zone of the ocular surface that reported to be a predictive area in detection of dry eye subtypes [41]. Each point marked represents an area of $3 \times 3$ pixels so that temperature was an average of nine pixels:-

$80 \quad 1$ - Temporal limbus (LT) 
812 - Nasal limbus (LN)

823 - Extreme temporal conjunctiva (T1)

834 - Extreme nasal conjunctiva (T4)

845 - Most inferior point of the ocular surface

85

86

'Insert Fig. 1 here'

87

88 Once the marking of ROI was completed, OST acquisition and processing was performed

89 automatically by double clicking the last point marked (point 5 ) to activate the OST Analysis V2

90 program and process all the 300 frames. All frame marking and data processing were undertaken

91 by a single examiner (LL). Ten OST indices of the ocular surface were generated as shown in

92 Table 1. In this study, GCC denotes the temperature of the geometric center of the cornea,

93 obtained midway between LT and LN. The OST indices were selected to document the whole

94 inferior zone of the exposed ocular surface within ROI and to include as far as possible, all the

95 reported temperature metrics [23, 26-33]. All the ten OST indices extracted by the 'diamond'

96 method has shown to be highly repeatable in assessing healthy and dry eyes [35] in terms of inter-

97 image, inter-examiner and intra-examiner variability.

98

99

'Insert Table 1 here'

100

\section{Data Analysis}

102 Data on all 62 dry eye subjects and 63 controls were tabulated and analysed. The ten OST indices

103 were studied in two aspects: static and dynamic measures. To prevent difficulties arising when

104 non-independent data were collected from both eyes, only data obtained from right eye were used

105 in the analysis [42].

106

107 Static measures were study of absolute OST at $\mathrm{t}=0 \mathrm{~s}, 5 \mathrm{~s}$ and $10 \mathrm{~s}$ ( 3 static attributes) after eye

108 opening. Data were obtained directly from the raw data. As we had ten OST indices, 30 static

109 temperature metrics were generated. For example, GCC temperature at $0 \mathrm{~s}, 5 \mathrm{~s}$ and $10 \mathrm{~s}$ were

110 labelled as GCC-0, GCC-5 and GCC-10 respectively.

111

112 Dynamic measures were study of temperature change over time. One phase exponential curve

113 was fitted to the temperature vs. time data for each series of images using JMP 11 according to the

114 following model:

115

116

Temperature $=a+b^{*} \operatorname{Exp}\left(c^{*}\right.$ time $)$

117

118 We adopted the terminology used by JMP (http://www.jmp.com; SAS Institute Inc., USA) as used

119 the terms 'asymptote' (a), 'scale' (b) and 'growth rate' * [3 dynamic attributes] (c). Again, as we had 
120 ten OST indices, in total 30 dynamic temperature metrics were generated. For example, asymptote, scale and growth rate for GCC temperature were labelled as GCC-A, GCC-S and GCC-GR respectively. The efficacy of ocular thermography in diagnosing DED was then evaluated in two phases: singly and in combination.

\section{Phase 1: Evaluating the efficacy of the $\mathbf{3 0}$ static- and $\mathbf{3 0}$ dynamic-metrics when applied} singly

Findings on dry eye subjects and their controls for each metric were compiled. Using GraphPrism 6 (www.graphpad.com; GraphPad Software Inc., USA), a range of testing threshold/criterion with their sensitivity, specificity, area under the ROC curve (AUC), predictive values $[43,44]$ were then been derived. Receiver operating characteristics (ROC) $[45,46]$ curves, which determine the sensitivity and specificity of the measurement in diagnosing dry eye [47] were plotted for all 30 static and 30 dynamic-metrics and AUC was extracted using trapezoidal numerical integration. The AUC (range: 50 to 100 in percentage) is a quantitative representation of overall test accuracy, where values from 50 to 70 represent low accuracy, values from 70 to 90 represent tests that are useful for some purposes/moderate accuracy, and values $>90$ represent tests with high accuracy [48]. Metrics that has AUC of 70 or above were selected.

Although AUC is one of the main parameters of ROC, to better evaluate the performance of the technique as a detector, (i.e. the discrimination between dry eyes from those of normal subjects) it is important to determine the cutoff values, selected as the one that optimizes both sensitivity and specificity $[43,49]$. Sensitivity is the proportion of actual positives (i.e. dry eye subjects) that are correctly identified, while specificity is the proportion of actual negatives (i.e. normal subjects) that are correctly identified. To facilitate the detector performance comparison, we evaluated every tested metric by means of a set of statistical tools [50], namely the Youden's index (Y) [51] and the discrimination power (DP) [50].

Youden's index evaluates the algorithm's ability to avoid failure and follows the expression

$$
Y=\text { sensitivity }+ \text { specificity }-100
$$

Its value ranges from 0 to 100 in percentage, and has a zero value when a diagnostic test gives the same proportion of positive results for groups with and without the disease, i.e the test is useless. A value of 100 indicates that there are no false positives or false negatives, i.e. the test is perfect. Youden's index is often used in conjunction with ROC analysis [52]. Graphically, $Y$ is the maximum vertical distance between the ROC curve and the diagonal line. Cutoff values of the selected metrics can then be determined as the criterion that maximized the Youden index: max (sensitivityc + specificity $c-100$ ), where $c$ ranges over all possible criterion values [51]. The cutoff values that achieves this maximum is referred to as the optimal cutoff because it is the cutoff values that 
159 optimizes the metric's differentiating ability when equal weight is given to sensitivity and specificity $160 \quad[43,49,52-54]$.

161

162 DP is a measurement that summarizes sensitivity and specificity of the technique,

163

164

$$
D P=\sqrt{ } 3 / \pi(\log X+\log Y)
$$

165

166

Where $\mathrm{X}=$ sensitivity / (100-sensitivity) and $\mathrm{Y}=$ specificity $/(100$-specificity). Values of $\mathrm{DP}<1$ indicate poor discrimination performance, DP $<2$ indicates limited performance, DP $<3$ considered to be a fair discrimination, while values above 3 are classified as good.

170 Calculating the Youden's index and DP could give clearer evidence of a test performance [49]. In 171 this report, AUC was used as an indicator for test accuracy [48] and where the AUC does not show much difference, Youden's index and DP were used as indicators for test performance [49].

\section{Phase 2: Evaluating the best combined temperature metrics in screening DED}

175 The diagnostic power of the metrics can be possibly maximized by combining them. In this part of

176 the study, we sought to evaluate if AUC can be further maximised by a factor analysis model using 177 principal component analysis [55-56] through Excel's 'solver' function (Microsoft Excel 2013, USA).

178 The analysis was developed for each dataset in order to reduce the dimensionality of the variables 179 down to one or two factors combining these variables. This will help to determine the best detectors 180 for dry eye. Again, data was first tabulated on the 30 static- and dynamic-metrics. A range of 181 testing threshold/criterion was encapsulated in 0.1 intervals. Using Excel spreadsheet, sensitivity, 182 specificity and AUC were derived for all the metrics. After which, a tool in the Excel spreadsheet 183 'solver' was used to test on all possible combinations within the 30 static- and dynamic-metrics that could possibly maximising the AUC and determine the best detectors.

\section{Results}

187 Phase 1: Evaluating the efficacy of the $\mathbf{3 0}$ static- and $\mathbf{3 0}$ dynamic-metrics when applied 188 singly

189 Figure 2 shows the ROC curves for the 30 static metrics, grouped in three different time points $(0 \mathrm{~s}$, $1905 \mathrm{~s}$ and $10 \mathrm{~s}$ ). Figure 3 shows the ROC curves for the 30 dynamic metrics, grouped into its three 191 attributes.

193 Based on Figure 2, the best AUC for static metrics were T4-5 and T4-10 with AUC of $72 \%$ (95\% Cl: 19463 to $81 \%$ ) and $73 \%$ (64 to $82 \%$ ) respectively, indicating the tests were useful for some 195 purpose/moderate accuracy [48]. AUC for the rest of the static metrics lied below $70 \%$ indicating 196 low accuracy. For example, AUC for T4-0 was 69\% (60 to 79\%). Based on Figure 3, the AUC for 197 dynamic metrics ranged from 50 to 64 , indicating that all dynamic metrics were of low accuracy as 198 their AUC lied below $70 \%$ [48]. 
199

200

'Insert Fig. 2 and 3 here'

201

202 Table 2 shows a summary of AUC, sensitivity, specificity, Youden's index, DP and the selected

203 cutoff values for the 30 static metrics. The best results were, again, obtained for T4- 5 and T4-10

204 metrics with DP of 1.07 and 1.05 respectively indicating limited performance. DP for the rest of the

205 static metrics were less than 1 indicating poor discrimination performance including T4-0 [50].

206 Youden's index for T4-5 and T4-10 was also found to be highest of all (37.9 and 39.5 respectively). T4-0 had lower DP of 0.79 and Youden's index of 34.4.

208

209

'Insert Table 2 here'

210

211 When the cutoff values for T4-5 was set at $34.7^{\circ} \mathrm{C}$ (i.e., values $<34.8^{\circ} \mathrm{C}$; Table 2 ), sensitivity and 212 specificity was $87.1 \%$ ( 76.2 to $94.3 \%$ ) and $50.8 \%$ (37.9 to $63.6 \%)$ respectively and when the cutoff 213 values for $\mathrm{T} 4-10$ was set at $34.5^{\circ} \mathrm{C}$ (i.e., values $<34.6^{\circ} \mathrm{C}$; Table 2 ), sensitivity and specificity was $21477.6 \%(64.7$ to $87.5 \%)$ and $61.9 \%(48.8$ to $73.9 \%)$ respectively.

215

216

'Insert Table 3 here'

217

218 Table 3 shows a summary of AUC, sensitivity, specificity, Youden's index, DP and the selected

219 cutoff values for the 30 dynamic metrics. All dynamic metrics were shown to be of low accuracy, with AUC below $70 \%$ [48]. The DP for all dynamic metrics ranged from 0.20 to 0.69 indicating poor discrimination performance as they were less than 1 [50]. Youden's index was also found to be low for all dynamic metrics ranging 8.6 to 27.9 .

223

224

\section{Phase 2: Evaluating the best combined temperature metrics in screening DED}

225

AUC for static metrics at $0 \mathrm{~s}$ can be increased to $71 \%$ by a combined metrics in the expression of $0.95 \mathrm{GCC}+0.19 \mathrm{MOST}+0.26 \mathrm{MinT}+0.50 \mathrm{MaxT}+0.09 \mathrm{~T} 1+0.94 \mathrm{~T} 4+0.04 \mathrm{CT}+0.18 \mathrm{LT}+0.07 \mathrm{LN}+0.37 \mathrm{CN}$.

227

AUC for static metrics at $5 \mathrm{~s}$ can be increased to $72 \%$ by a combined metrics in the expression of $0.02 \mathrm{GCC}+0.15 \mathrm{MOST}+0.04 \mathrm{MinT}+0.65 \mathrm{MaxT}+0.27 \mathrm{~T} 1+0.90 \mathrm{~T} 4+0.26 \mathrm{CT}+0.12 \mathrm{LT}+0.11 \mathrm{LN}+0.19 \mathrm{CN}$.

230

AUC for static metrics at $10 \mathrm{~s}$ can be increased to $73 \%$ by a combined metrics in the expression of $0.03 \mathrm{~T} 1+0.98 \mathrm{~T} 4+0.06 \mathrm{CT}+0.02 \mathrm{LT}+0.02 \mathrm{LN}+0.05 \mathrm{CN}$.

233

It was shown that T4 was the main contributor to AUC for static metrics at all three time points. However, by just looking at the AUC at respective metric (without combining them), the AUC for T4 were shown to be very similar: $69 \%$ at $0 \mathrm{~s}, 72 \%$ at $5 \mathrm{~s}$ and $73 \%$ at $10 \mathrm{~s}$ (Table 2). It was therefore concluded that combining metrics was not able to meaningfully improve AUC for static measures. 
239 On the other hand, AUC for dynamic metrics for asymptote can be increased to $53 \%$ by a

240 combined metrics in the expression of

$2410.31 \mathrm{GCC}+0.34 \mathrm{MOST}+0.55 \mathrm{MinT}+0.23 \mathrm{MaxT}+0.28 \mathrm{~T} 1+0.87 \mathrm{~T} 4+0.84 \mathrm{CT}+0.25 \mathrm{LT}+0.02 \mathrm{LN}+0.68 \mathrm{CN}$.

242

243 AUC for dynamic metrics for scale can be increased to $56 \%$ by a combined metrics in the

244 expression of

$245 \quad 0.21 \mathrm{GCC}+0.06 \mathrm{MOST}+0.04 \mathrm{MinT}+0.06 \mathrm{MaxT}+0.92 \mathrm{~T} 4$.

246

247 AUC for dynamic metrics for growth rate can be increased to $51 \%$ by $1.00 T 4$. It was again shown

248 that, T4 was the main contributor to AUC for dynamic metrics at all three attributes. Similarly, by

249 just looking at the AUC at respective metric (without combining them), the AUC for T4 were shown

250 to be very similar: $59 \%$ for asymptote, $61 \%$ for scale and $50 \%$ for growth rate (Table 3 ). It was

251 again concluded that combining metrics was not able to meaningfully improve the AUC for dynamic

252 measures.

253

254

'Insert Fig. 4 and 5 here'

255

256 ROC curves on T4 metrics alone were then plotted and shown in Figure 4 and 5 with a summary of 257 their AUC. It was clear that T4 metrics (static) were good detectors for DED as points were far 258 above the diagonal line in ROC curve [45] (Fig. 4) as compared to T4 metrics (dynamic) where 259 points were on / fairly above the diagonal line (Fig. 5) indicating poor detectors for DED [45].

260

\section{Discussion}

262 This is the first study to demonstrate that measuring temperature at the extreme nasal conjunctiva

263 was able to discriminate mild to moderate dry eye from non-DED patients. The test was

264 comparable to other well established methods in testing tear stability based on different principles,

265 such as tear break-up time (BUT) $[21,57,58]$ and non-invasive tear break-up time (NIBUT) [58]

266 (Table 4). A cutoff value of $34.7^{\circ} \mathrm{C}$ for $\mathrm{T} 4-5$ temperature has given higher sensitivity as compared

267 to wet BUT and dry BUT [57], BUT [21,58] and NIBUT [58]. On the other hand, a cutoff value of

$26834.5^{\circ} \mathrm{C}$ for $\mathrm{T} 4-10$ temperature had lower sensitivity in general when compared with above-

269 mentioned tests but its specificity was better than wet BUT [57], BUT [21,58] and NIBUT [58]

270 (Table 4).

271

272 'Insert Table 4 here'

273

274 Static metrics were found to have better efficacy in diagnosing DED as compared to dynamic

275 metrics. It was sufficient to perform the test singly as combined metrics was not successful to

276 increase its performance. The limited discrimination performance of any single method highlights

277 the complexity of diagnosing DED. The 30 tested dynamic metrics were shown to have low efficacy

278 in diagnosing DED (singly and in combination) and deserved no further discussion. 
It has been reported that temperature at the conjunctiva was higher than that of the central corneal $[37,59]$. Although the reasons remains unclear, the temperature of the nasal conjunctiva was reported to be higher than that of the temporal conjunctiva because of the influence of greater blood flow and vascularization in the nasal conjunctiva [26]. More large vessels (eg. the dorsal nasal artery and the angular artery) are situated at the nasal side of the eye. In addition, the medial rectus muscle has two anterior ciliary arteries, whereas the lateral rectus muscle has only one artery. All these anatomical factors has caused a more vascularised nasal conjunctiva with higher blood flow [26] and hence causing a higher evaporation rate / less stable tear film at T4. Further studies would be required to confirm these postulation. Nevertheless, the temperature changes at nasal conjunctiva may also be contributed by other factors such as allergy rather than dry eye and warranted further investigations.

\section{Our study was in agreement with past studies [26,27] i.e., measuring OST can be a good} diagnostic tool for dry eye. Sensitivity and specificity of Tomey IR thermographer tested at GCC was reported to be $83 \%$ and $80 \%$ respectively using a cutoff value of $0.13{ }^{\circ} \mathrm{C}$ but reduced to $80 \%$ and $73 \%$ respectively using a cutoff value of $0.11^{\circ} \mathrm{C}$ [26]. The values derived in Kamao et al's [26] study was not defined clearly but believed was a decrease in dynamic temperature over 10 seconds (for cutoff value of $0.13^{\circ} \mathrm{C}$ ) and 5 seconds (for cutoff value of $0.11^{\circ} \mathrm{C}$ ) respectively. Using a custom-designed IR thermal image system, sensitivity and specificity of a combined temperature metrics (temperature difference and compactness values) were $84 \%$ and $83 \%$ respectively with unclear cutoff value [27]. Limited temperature metrics were included in the above mentioned studies as compared to sixty temperature metrics in the current report. Different in findings as compared to the current report could be due to different in methodology and subjects recruited. Ocular thermographers with lower resolution of $400(\mathrm{H}) \times 240(\mathrm{~V})$ pixels and $320(\mathrm{H}) \times 240(\mathrm{~V})$ pixels in Kamao et al's [26] and Su et al's [27] studies respectively may have hindered the visibility of the anatomical structures of the ocular surface and created errors in OST acquisition. Dry eye subjects recruited by both studies were much older (mean age 52.9 years for dry eye and 42.7 years for control subjects [26] and mean age of 49 years for dry eye and 34 years for controls [27]) and the two groups were not age-matched. This is important because OST was reported to decrease with age at a rate of $-0.010{ }^{\circ} \mathrm{C} /$ year [39]. Differences in OST between groups may be age-related rather than to the disease itself.

Other tests evaluating DED such as tear osmolarity and tear evaporation rate measurement have been reported to have better diagnostic ability. Using a threshold value of $312 \mathrm{mOsms} / \mathrm{L}$, tear osmolarity had sensitivity of $73 \%$ and specificity of $92 \%$ as compared to other tests (54\% for corneal staining, $60 \%$ for conjunctival staining and $61 \%$ for meibomian gland grading on sensitivity; $45 \%$ for tear break-up time and $51 \%$ for Schirmer test on specificity [21]. On the other hand, values of $41 \mathrm{~g} / \mathrm{m}(-2) / \mathrm{h}$ for tear evaporation rate has found to give sensitivity of $96 \%$ and specificity of $67 \%$ [47]. 
This paper presented a comprehensive study of the diagnostic ability for IR ocular thermography in screening DED. All dry eye patients were mild to moderate with no inflamed meibomian glands. We acknowledged that many disease severity criteria are confounded by complex disease subtypes and a lack of standardisation, and the selection of single criteria for assessment of disease severity is therefore fraught with difficulties $[8,60,61]$.

The results of this study suggest that IR ocular thermography is a suitable test to be incorporated in the non-invasive diagnostic assessment of dry eye. It is repeatable, rapid, and easy to use and in this study, shown to give good sensitivity of specificity in diagnosing DED. Future studies on dry eye screening using ocular thermography should include temperature of the conjunctiva. T4-5 and T4-10 metrics are simple, static measures and we speculate that they could be used in combination with other conventional tests to further refine diagnostic discrimination for DED. Since this was a preliminary study, we attempted to standardize every aspect of our testing protocol (e.g., temperature and humidity controlled room, 20 minutes of room acclimation) in order to reduce testing variability as much as possible. While this is a common research strategy, additional work is needed to determine if our findings hold up in a normal clinic environment. Nevertheless, our overall findings do indicate that ocular thermography may be useful for understanding dry eye in clinical practice.

\section{Acknowledgements}

This study was funded by Singapore ToteBoard Organisation no. LS/CLS/TM/2009/007. The authors wish to thank Dr. Cai Zhi Qiang from School of Electronic and Electrical Engineering in writing the OST analysis V2 program using MatLab Simulink 7.11.0 (R2010b) and Dr. Robert Straughan from School of Mathematics and Science for his valuable statistical advice.

\section{Financial disclosures}

The authors have no financial interest in any of the materials used in this study.

\section{Conflict of interest statement}

No conflicting relationship exists for any author.

\section{References}

[1] Tan LL, Morgan PB, Cai ZQ, Straughan RA. Prevalence of and risk factors for symptomatic dry eye disease in Singapore. Clin Exp Optom 2015; 98 (1): 45-53.

[2] DEWS. The Epidemiology of dry eye disease: Report of the Epidemiology Subcommittee of the International dry eye workshop. Ocular Surface 2007a; 5(2): 93-107.

[3] Miljanovic B, Dana R, Sullivan DA, Schaumberg DA. Impact of dry eye syndrome on visionrelated quality of life among women. Invest Ophthalmol Vis Sci 2004; 45: 3740. 
361

362

363

364

365

366

367

368

369

370

371

372

373

374

375

376

377

378

379

380

381

382

383

384

385

386

387

388

389

390

391

392

393

394

395

396

397

398

399

400

401

402

403

404

405

406

407

408

409

410

411

412

413

414

415

416

417

418

419

420
[4] Miljanovic B, Sullivan D, Schaumberg DA. Impact of dry eye syndrome on vision-related quality of life. Am J Ophthalmol 2007; 143(3): 409-15.

[5] Pflugfelder SC. Prevalence, burden, and pharmacoeconomics of dry eye disease. Am J Manag Care 2008; 14: S102-106.

[6] Tong L, Waduthantri S, Wong TY, Saw SM, Wang JJ, Rosman M, Lamoureux E. Impact of symptomatic dry eye on vision-related daily activities: The Singapore Malay Eye Study. Eye 2010; 24(9): 1486-91.

[7] Savini G, Prabhawasat P, Kojima T, Grueterich M, Espana E, Goto E. The challenge of dry eye diagnosis. Clin Ophthalmol 2008; 2(1): 31-55.

[8] DEWS. Methodologies to diagnose and monitor dry eye disease: Report of the Diagnostic Methodology Subcommittee of the International Dry Eye Workshop. Ocular Surface 2007b; 5(2): 106-123.

[9] Tomlinson A, Hair M, McFadyen A. Statistical approaches to assessing single and multiple outcome measures in dry eye therapy and diagnosis. Ocular Surface 2013; 11(4): 267-84.

[10] Goren MB and Goren SB. Diagnostic-tests in patients with symptoms of keratoconjunctivitis sicca. Am J Ophthalmol 1988; 106(5): 570-4.

[11] Kallarackal GU, Ansari EA, Amos N, Martin JC, Lane C, Camilleri JP. A comparative study to assess the clinical use of Fluorescein Meniscus Time (FMT) with Tear Break up Time (TBUT) and Schirmer's tests (ST) in the diagnosis of dry eyes. Eye 2002; 16(5): 594-600.

[12] Cho P, Brown B, Chan I, Conway R, Yap M. Reliability of the tear break-up time technique of assessing tear stability and the locations of the tear break-up in Hong Kong Chinese. Optom Vis Sci 1992; 69(11): 879-85.

[13] Cho P. Reliability of a portable nonimvasive tear break-up time test on Hong Kong Chinese. Optom Vis Sci 1993; 70(12): 1049-54.

[14] Cho P and Brown B. Review of the tear break-up time and a closer look at the tear break-up time of Hong Kong Chinese. Optom Vis Sci 1993; 70(1): 30-38.

[15] Saleh TA, McDermott B, Bates AK, Ewings P. Phenol red thread test vs Schirmer's test: a comparative study. Eye 2006; 20(8): 913-5.

[16] Nelson JD, Helms H, Fiscella R, Southwell Y, Hirsch JD. A new look at dry eye disease and its treatment. Advances in Therapy 2000; 17(2): 84-93.

[17] Begley CG, Chalmers RL, Abetz L, Venkataraman K, Mertzanis P, Caffery BA, Snyder C, Edrington T, Nelson D, Simpson T. The relationship between habitual patient-reported symptoms and clinical signs among patients with dry eye of varying severity. Invest Ophthalmol Vis Sci 2003; 44(11): 4753-61.

[18] Nichols KK, Nichols JJ, Mitchell GL. The lack of association between signs and symptoms in patients with dry eye disease. Cornea 2004; 23(8): 762-70.

[19] Moore JE, Graham JE, Goodall EA, Dartt DA, Leccisotti A, McGilligan VE, Moore TCB. Concordance between common dry eye diagnostic tests. Br J Ophthalmol 2009; 93(1): 66-72.

[20] Cardona G, Marcellan C, Fornieles A, Vilaseca M, Quevedo L. Temporal Stability in the Perception of Dry Eye Ocular Discomfort Symptoms. Optom Vis Sci 2010; 87(12): 1023-9.

[21] Lemp MA, Bron AJ, Baudouin C, Del Castillo JMB, Geffen D, Tauber J, Foulks GN, Pepose JS, Sullivan BD. Tear Osmolarity in the Diagnosis and Management of Dry Eye Disease. Am J Ophthalmol 2011; 151(5): 792-8. 
421

[22] Sullivan BD, Crews LA, Messmer EM, Foulks GN, Nichols KK, Baenninger P, Geerling G, Figueiredo F, Lemp MA. Correlations between commonly used objective signs and symptoms for the diagnosis of dry eye disease: clinical implications. Acta Ophthalmol 2014; 92(2): 161-6.

[23] Craig JP, Singh I, Tomlinson A, Morgan PB, Efron N. The role of tear physiology in ocular surface temperature. Eye 2000; 14: 635-41.

[24] Labbe A, Brignole-Baudouin F, Baudouin C. Ocular surface investigations in dry eye. J Fr Ophtalmol 2007; 30(1): 76-97.

[25] Purslow $C$ and Wolffsohn JS. The relation between physical properties of the anterior eye and ocular surface temperature. Optom Vis Sci 2007; 84(3): 197-201.

[26] Kamao T, Yamaguchi M, Kawasaki S, Mizoue S, Shiraishi A, Ohashi Y. Screening for Dry Eye With Newly Developed Ocular Surface Thermographer. Am J Ophthalmol 2011; 151(5): 78291.

[27] Su TY, Hwa CK, Liu PH, Wu MH, Chang DO, Su PF, Chang SW, Chiang HK. Noncontact detection of dry eye using a custom designed infrared thermal image system. J Biomed Opt 2011; 16(4): 046001-6.

[28] Fujishima H, Toda I, Yamada M, Sato N, Tsubota K. (1996). Corneal temperature in patients with dry eye evaluated by infrared radiation thermometry. Br J Ophthalmol 1996; 80(1): 29-32.

[29] Morgan PB, Tullo AB, Efron N. Ocular surface cooling in dry eye - a pilot study. J Br Contact Lens Assoc 1996; 19(1): 7-10.

[30] Zelichowska B, Rozycki R, Tlustochowicz M, Kujawa A, Kalicki B, Murawski P. The usefulness of thermography in the diagnosis of dry eye syndrome. Klin Oczna 2005; 107(7): 483-7

[31] Morgan PB, Soh MP, Tullo AB, Efron N. Potential applications of ocular thermography. Optom Vis Sci 1993; 70(7): 568-76.

[32] Morgan PB, Tullo AB, Efron N. Infrared thermography of the tear film in dry eye. Eye 1995; 9 : 615-18.

[33] Singh G and Bhinder HS. Comparison of noncontact infrared and remote sensor thermometry in normal and dry eye patients. Eur J Ophthalmol 2005a; 15(6): 668-73.

[34] DEWS. The definition and classification of dry eye disease: Report of the Definition and Classification Subcommittee of the International Dry Eye Workshop. Ocular Surface 2007c; 5(2): 73-92.

[35] Tan LL, Sanjay S, Morgan PB. Repeatability of infrared ocular thermography in assessing healthy and dry eyes. Cont Lens Anterior Eye 2016; 39(4):284-92.

[36] Golding TR and Brennan NA. Diagnostic-accuracy and inter-correlation of clinical-tests for dry eye. Invest Ophthalmol Vis Sci 1993; 34(4): 823-6.

[37] Mapstone R. Determinants of corneal temperature. Br J Ophthalmol 1968; 52(10): 729-41.

[38] Morgan PB. Ocular thermography in health and disease. PhD Thesis 1994. University of Manchester.

[39] Morgan PB, Soh MP, Efron N. Corneal surface temperature decreases with age. Cont Lens Anterior Eye 1999; 22(4): 11-13. 
479

480

481

482

483

484

485

486

487

488

489

490

491

492

493

494

495

496

497

498

499

500

501

502

503

504

505

506

507

508

509

510

511

512

513

514

515

516

517

518

519

520

521

522

523

524

525

526

527

528

529

530

531

532

533

534

535

536

537

[40] Pattmoller J, Wang J, Zemova E, Seitz B, Eppig T, Langenbucher A, Szentmary N. Correlation of corneal thickness, endothelial cell density and anterior chamber depth with ocular surface temperature in normal subjects. Z Med Phys 2014; 10(5): 1-8.

[41] Fenner BJ and Tong L. Corneal staining characteristics in limited zones compared with whole cornea documentation for the detection of dry eye subtypes. Invest Opthalmol Vis Sci 2013; 54(13): 8013-19.

[42] Ray WA and O'Day DM. Statistical analysis of multi-eye data in ophthalmic research. Invest Ophthalmol Vis Sci 1985; 26(8): 1186-8.

[43] Bland JM and Altman DG. Statistic Notes: Diagnostic tests 1: sensitivity and specificity. BMJ 1994a; 308: 1552.

[44] Bland JM and Altman DG. Statistics Notes: Diagnostic tests 2: predictive values. BMJ 1994b; 309: 102.

[45] Bland JM and Altman DG. Statistics Notes: Diagnostic tests 3: receiver operating characterisctic plots. BMJ 1994c; 309: 188.

[46] Zweig MH and Campbell G. Receiver-operating characteristic (ROC) plots: a fundamental evaluation tool in clinical medicine. Clinical Chemistry 1993; 39: 561-77.

[47] Khanal S, Tomlinson A, McFadyen A, Diaper C, Ramaesh K. Dry eye diagnosis. Invest Ophthalmol Vis Sci 2008; 49(4): 1407-14.

[48] Wians FH. Clinical Laboratory Tests: Which, Why, and What Do The Results Mean? Lab Medicine 2009; 40 (2): 105-113.

[49] Alonso-Caneiro D, Turuwhenua J, Iskander DR, Collins MJ. Diagnosing dry eye with dynamicarea high-speed videokeratoscopy. J Biomed Opt 2011; 16(7).

[50] Sokolova M, Japkowicz N, Szpakowicz S. Beyond accuracy, f-score and roc: a family of discriminant measures for performance evaluation. Al 2006: Advances in Artificial Intelligence 2006; 4304(1): 1015-1021.

[51] Youden WJ. An index for rating diagnostic tests. Cancer 1950; 3: 32-35.

[52] Schisterman EF, Perkins NJ, Liu A, Bondell H. Optimal cut-point and its corresponding Youden Index to discriminate individuals using pooled blood samples. Epidemiology 2005; 16 : 73-81.

[53] Faraggi $D$. The effect of random measurement error on receiver operating characteristic (ROC) curves. Statistics in Medicine 2000; 19: 61-70.

[54] Reiser B. Measuring the effectiveness of diagnostic markers in the presence of measurement5error through the use of ROC curves. Statistics in Medicine 2000; 19: 21152129.

[55] Kass RA and 6insley HEA. Factor analysis. J Leisure Res 1979; 11: 120-38.

[56] Everitt BS and Dunn G. Applied multivariate data analysis. London, Edward Arnold 1991.

[57] Kim KT, Kim JH, Kong YT, Chae JB, Hyung S. Reliability of a new modified tear breakup time method: dry tear breakup time. Graefes Arch Clin Exp Ophthalmol 2015; 253(8):1355-61.

[58] Yeh TN, Graham AD, Lin MC. Relationships among Tear Film Stability, Osmolarity, and Dryness Symptoms. Optom Vis Sci 2015; 92(9): e264-72. 
538 [59] Alio $\mathrm{J}$ and Padron M. Normal variations in the thermographic pattern of the orbito-ocular region. Diagnostic Imaging 1982; 51(2): 93-98.

[60] Schein OD, Tielsch JM, Munoz B, BandeenRoche K, West S. Relation between signs and symptoms of dry eye in the elderly - A population-based perspective. Ophthalmology 1997; 104(9): 1395-1401.

[61] Sullivan BD, Whitmer D, Nichols KK, Tomlinson A, Foulks GN, Geerling G, Pepose JS, Kosheleff V, Porreco A, Lemp MA. An Objective Approach to Dry Eye Disease Severity. Invest Ophthalmol Vis Sci 2010; 51(12): 6125-30. 
Table 1

The ten OST indices studied.

\begin{tabular}{ll}
\hline OST indices & Description \\
\hline GCC & Geometric center of the cornea (midway between LT and LN) \\
MOST & Mean OST of the ROI \\
T1 & Extreme temporal conjunctiva \\
T4 & Extreme nasal conjunctiva \\
CT & Mid-temporal conjunctiva (midway between T1 and LT) \\
LT & Temporal limbus \\
LN & Nasal limbus \\
CN & Mid-nasal conjunctiva (midway between T4 and LN) \\
MinT & Minimum temperature of ROI \\
MaxT & Maximum temperature of ROI \\
\hline
\end{tabular}


Table 2

Test effectiveness of static metrics at 0,5 and $10 \mathrm{~s}$. AUC, sensitivity, specificity, Youden's index (Y), discrimination power (DP) and the selected cutoff values are shown.

\begin{tabular}{|c|c|c|c|c|c|c|}
\hline $\begin{array}{l}\text { Static metrics } \\
\text { at } 0 \mathrm{~s}\end{array}$ & AUC, $\%(95 \% \mathrm{Cl})$ & Cutoff values, ${ }^{\circ} \mathrm{C}$ & $\begin{array}{l}\text { Sensitivity, \% } \\
(95 \% \mathrm{Cl})\end{array}$ & $\begin{array}{l}\text { Specificity, \% } \\
(95 \% \mathrm{Cl})\end{array}$ & $Y$ & DP \\
\hline GCC-0 & 69 (60 to 78$)$ & $<34.3$ & 72.6 (59.8 to 83.2 ) & 60.3 (47.2 to 72.4$)$ & 32.9 & 0.77 \\
\hline MOST-0 & 68 (58 to 77 ) & $<34.7$ & 79.0 (66.8 to 88.3 ) & 54.0 (40.9 to 66.6 ) & 33.0 & 0.82 \\
\hline MinT-0 & 67 (58 to 77 ) & $<34.0$ & 79.0 (66.8 to 88.3$)$ & 57.1 (44.1 to 69.5$)$ & 36.2 & 0.89 \\
\hline MaxT-0 & 67 (57 to 76$)$ & $<35.7$ & 82.3 (70.5 to 90.8$)$ & 47.6 (34.9 to 60.6 ) & 29.9 & 0.79 \\
\hline T1-0 & 66 (57 to 76 ) & $<35.2$ & $61.3(48.1$ to 73.4$)$ & 71.4 (58.7 to 82.1$)$ & 32.7 & 0.76 \\
\hline T4-0 & 69 (60 to 79$)$ & $<34.5$ & 69.4 (56.4 to 80.4$)$ & 65.1 (52.0 to 76.7 ) & 34.4 & 0.79 \\
\hline CT-0 & 68 (58 to 77 ) & $<34.6$ & 56.5 (43.3 to 69.0$)$ & 74.6 (62.1 to 84.7$)$ & 31.1 & 0.74 \\
\hline LT-0 & 67 (57 to 77 ) & $<34.5$ & 79.0 (66.8 to 88.3$)$ & 54.0 (40.9 to 66.6$)$ & 33.0 & 0.82 \\
\hline LN-0 & 65 (55 to 75 ) & $<34.7$ & 64.5 (51.3 to 76.3 ) & 63.5 (50.4 to 75.3 ) & 28.0 & 0.63 \\
\hline $\mathrm{CN}-\mathrm{O}$ & 68 (58 to 77 ) & $<35.4$ & 83.9 (72.3 to 92.0$)$ & 52.4 (39.4 to 65.1$)$ & 36.3 & 0.96 \\
\hline $\begin{array}{l}\text { Static metrics } \\
\text { at } 5 \mathrm{~s}\end{array}$ & AUC, $\%(95 \%$ Cl) & Cutoff values, ${ }^{\circ} \mathrm{C}$ & $\begin{array}{l}\text { Sensitivity, \% } \\
\text { (95\% CI) }\end{array}$ & $\begin{array}{l}\text { Specificity, \% } \\
(95 \% \mathrm{CI})\end{array}$ & $Y$ & DP \\
\hline GCC-5 & 68 (58 to 77 ) & $<33.9$ & 67.7 (54.7 to 79.1$)$ & 65.1 (52.0 to 76.7 ) & 32.8 & 0.75 \\
\hline MOST-5 & 66 (57 to 76$)$ & $<33.9$ & 46.8 (34.0 to 59.9 ) & 84.1 (72.7 to 92.1$)$ & 30.9 & 0.85 \\
\hline MinT-5 & 63 (53 to 73) & $<32.9$ & 41.9 (29.5 to 55.2$)$ & 82.5 (70.9 to 91.0$)$ & 24.5 & 0.68 \\
\hline MaxT-5 & 68 (59 to 77 ) & $<35.6$ & 77.4 (65.0 to 87.1$)$ & 54.0 (40.9 to 66.6$)$ & 31.4 & 0.77 \\
\hline T1-5 & 66 (56 to 75 ) & $<35.1$ & 59.7 (46.5 to 72.0$)$ & 71.4 (58.7 to 82.1 ) & 31.1 & 0.72 \\
\hline T4-5 & 72 (63 to 81$)$ & $<34.8$ & 87.1 (76.2 to 94.3$)$ & 50.8 (37.9 to 63.6 ) & 37.9 & 1.07 \\
\hline CT-5 & 66 (56 to 75$)$ & $<34.7$ & 75.8 (63.3 to 85.8$)$ & 52.4 (39.4 to 65.1$)$ & 28.2 & 0.68 \\
\hline LT-5 & 64 (54 to 74 ) & $<34.1$ & 72.6 (59.8 to 83.2 ) & 52.4 (39.4 to 65.1$)$ & 25.0 & 0.59 \\
\hline LN-5 & 63 (54 to 73 ) & $<34.4$ & 59.7 (46.5 to 72.0$)$ & 71.4 (58.7 to 82.1$)$ & 31.1 & 0.72 \\
\hline $\mathrm{CN}-5$ & 67 (57 to 76 ) & $<35.3$ & $85.5(74.2$ to 93.1$)$ & 47.6 (34.9 to 60.6 ) & 33.1 & 0.92 \\
\hline $\begin{array}{l}\text { Static metrics } \\
\text { at } 10 \mathrm{~s}\end{array}$ & AUC, $\%(95 \% \mathrm{Cl})$ & Cutoff values, ${ }^{\circ} \mathbf{C}$ & $\begin{array}{l}\text { Sensitivity, \% } \\
\text { (95\% Cl) }\end{array}$ & $\begin{array}{l}\text { Specificity, \% } \\
\text { (95\% Cl) }\end{array}$ & $Y$ & DP \\
\hline GCC-10 & 65 (55 to 74$)$ & $<33.9$ & 77.6 (64.7 to 87.5$)$ & 49.2 (36.4 to 62.1$)$ & 26.8 & 0.67 \\
\hline MOST-10 & 64 (54 to 74$)$ & $<33.9$ & 46.6 (33.3 to 60.1$)$ & 82.5 (70.9 to 91.0$)$ & 29.1 & 0.78 \\
\hline MinT-10 & 60 (50 to 70$)$ & $<32.7$ & 34.5 (22.5 to 48.1$)$ & 82.5 (70.9 to 91.0$)$ & 17.0 & 0.50 \\
\hline MaxT-10 & 69 (59 to 78$)$ & $<35.5$ & $75.9(62.8$ to 86.1$)$ & 55.6 (42.5 to 68.1$)$ & 31.4 & 0.75 \\
\hline $\mathrm{T} 1-10$ & 66 (56 to 75 ) & $<34.8$ & 44.8 (31.7 to 58.5 ) & 82.5 (70.9 to 91.0$)$ & 27.4 & 0.74 \\
\hline T4-10 & 73 (64 to 82 ) & $<34.6$ & 77.6 (64.7 to 87.5$)$ & 61.9 (48.8 to 73.9 ) & 39.5 & 1.05 \\
\hline CT-10 & 64 (54 to 74$)$ & $<34.2$ & 48.3 (35.0 to 61.8 ) & 81.0 (69.1 to 89.8$)$ & 29.2 & 0.76 \\
\hline LT-10 & 62 (52 to 72 ) & $<34.1$ & 74.1 (61.0 to 84.7$)$ & 47.6 (34.9 to 60.6 ) & 21.8 & 0.53 \\
\hline LN-10 & 62 (52 to 72 ) & $<34.3$ & 63.8 (50.1 to 76.0$)$ & 63.5 (50.4 to 75.3 ) & 27.3 & 0.62 \\
\hline $\mathrm{CN}-10$ & 67 (57 to 76 ) & $<35.2$ & 82.8 (70.6 to 91.4$)$ & 52.4 (39.4 to 65.1$)$ & 35.1 & 0.92 \\
\hline
\end{tabular}


Table 3

Test effectiveness for the dynamic metrics (A-asymptote, S-scale, GR-growth rate). Sensitivity, specificity, Youden's index (Y), discrimination power (DP) and the selected cutoff values are shown.

\begin{tabular}{|c|c|c|c|c|c|c|}
\hline $\begin{array}{l}\text { Dynamic } \\
\text { metrics-A }\end{array}$ & AUC, \% (95\% Cl) & Cutoff values, ${ }^{\circ} \mathrm{C}$ & $\begin{array}{l}\text { Sensitivity, \% } \\
(95 \% \mathrm{Cl})\end{array}$ & $\begin{array}{l}\text { Specificity, \% } \\
(95 \% \mathrm{Cl})\end{array}$ & $Y$ & DP \\
\hline GCC-A & 51 (41 to 61 ) & $>-0.2861$ & 40.3 (28.1 to 53.6 ) & 68.3 (55.3 to 79.4 ) & 8.6 & 0.21 \\
\hline MOST-A & 56 (46 to 66$)$ & $<-0.5155$ & 45.2 (32.5 to 58.3$)$ & 73.0 (60.4 to 83.4$)$ & 18.2 & 0.44 \\
\hline MinT-A & 54 (44 to 64 ) & $<-0.2918$ & 71.0 (58.1 to 81.8$)$ & 42.9 (30.5 to 56.0$)$ & 13.8 & 0.33 \\
\hline MaxT-A & 62 (52 to 72$)$ & $<-0.1750$ & 50.0 (37.0 to 63.0$)$ & 76.2 (63.8 to 86.0$)$ & 26.2 & 0.64 \\
\hline T1-A & 58 (48 to 68 ) & $<-0.1371$ & 45.2 (32.5 to 58.3$)$ & 81.0 (69.1 to 89.8$)$ & 26.1 & 0.69 \\
\hline T4-A & 59 (49 to 69 ) & $<-0.0921$ & 54.8 (41.7 to 67.5$)$ & 73.0 (60.4 to 83.4$)$ & 27.9 & 0.66 \\
\hline CT-A & 51 (41 to 61 ) & $<-0.6576$ & 17.7 (9.2 to 29.5$)$ & 92.1 (82.4 to 97.4$)$ & 9.8 & 0.51 \\
\hline LT-A & 52 (41 to 62 ) & $<-0.3737$ & 66.1 (53.0 to 77.7 ) & 46.0 (33.4 to 59.1$)$ & 12.2 & 0.28 \\
\hline LN-A & 60 (50 to 70$)$ & $<-0.0571$ & 82.3 (70.5 to 90.8$)$ & 34.9 (23.3 to 48.0$)$ & 17.2 & 0.50 \\
\hline $\mathrm{CN}-\mathrm{A}$ & 57 (47 to 67 ) & $<-0.4083$ & 40.3 (28.1 to 53.6$)$ & 74.6 (62.1 to 84.7$)$ & 14.9 & 0.38 \\
\hline $\begin{array}{l}\text { Dynamic } \\
\text { metrics-S }\end{array}$ & AUC, \% (95\% Cl) & Cutoff values, ${ }^{\circ} \mathrm{C}$ & $\begin{array}{l}\text { Sensitivity, \% } \\
(95 \% \mathrm{Cl})\end{array}$ & $\begin{array}{l}\text { Specificity, \% } \\
(95 \% \text { Cl) }\end{array}$ & $Y$ & DP \\
\hline GCC-S & 51 (41 to 61$)$ & $<0.3310$ & 45.2 (32.5 to 58.3$)$ & 63.5 (50.4 to 75.3$)$ & 8.7 & 0.20 \\
\hline MOST-S & 57 (46 to 67 ) & $>0.5252$ & 45.2 (32.5 to 58.3$)$ & 74.6 (62.1 to 84.7$)$ & 19.8 & 0.49 \\
\hline MinT-S & 55 (44 to 65 ) & $>0.3363$ & 67.7 (54.7 to 79.1$)$ & 46.0 (33.4 to 59.1$)$ & 13.8 & 0.32 \\
\hline MaxT-S & 64 (55 to 74$)$ & $>0.1571$ & 54.8 (41.7 to 67.5$)$ & 68.3 (55.3 to 79.4 ) & 23.1 & 0.53 \\
\hline T1-S & 59 (48 to 69 ) & $>0.1531$ & 48.4 (35.5 to 61.4$)$ & 77.8 (65.5 to 87.3 ) & 26.2 & 0.66 \\
\hline T4-S & 61 (51 to 71$)$ & $>0.0004$ & 62.9 (49.7 to 74.8$)$ & 58.7 (45.6 to 71.0 ) & 21.6 & 0.49 \\
\hline CT-S & 53 (43 to 63 ) & $>0.0101$ & 79.0 (66.8 to 88.3 ) & 33.3 (22.0 to 46.3 ) & 12.4 & 0.35 \\
\hline LT-S & 52 (42 to 62 ) & $>0.3985$ & 59.7 (46.5 to 72.0$)$ & 49.2 (36.4 to 62.1$)$ & 8.9 & 0.20 \\
\hline LN-S & 61 (51 to 71$)$ & $>0.3398$ & 64.5 (51.3 to 76.3$)$ & 57.1 (44.1 to 69.5 ) & 21.7 & 0.49 \\
\hline CN-S & 58 (48 to 68 ) & $>0.3175$ & 48.4 (35.5 to 61.4$)$ & 68.3 (55.3 to 79.4 ) & 16.6 & 0.39 \\
\hline $\begin{array}{l}\text { Dynamic } \\
\text { metrics-GR }\end{array}$ & AUC, \% (95\% Cl) & Cutoff values, ${ }^{\circ} \mathrm{C}$ & $\begin{array}{l}\text { Sensitivity, \% } \\
(95 \% \mathrm{Cl})\end{array}$ & $\begin{array}{l}\text { Specificity, \% } \\
(95 \% \text { Cl) }\end{array}$ & Y & DP \\
\hline GCC-GR & 54 (44 to 64$)$ & $>-0.1771$ & 61.3 (48.1 to 73.4 ) & 52.4 (39.4 to 65.1$)$ & 13.7 & 0.31 \\
\hline MOST-GR & 52 (42 to 63$)$ & $<-0.2436$ & 37.1 (25.2 to 50.3 ) & 74.6 (62.1 to 84.7$)$ & 11.7 & 0.30 \\
\hline MinT-GR & 55 (45 to 65 ) & $<-0.0322$ & 83.9 (72.3 to 92.0$)$ & $30.2(19.2$ to 43.0$)$ & 14.0 & 0.45 \\
\hline MaxT-GR & 53 (43 to 64$)$ & $>-0.3078$ & 85.5 (74.2 to 93.1$)$ & 33.3 (22.0 to 46.3 ) & 18.8 & 0.60 \\
\hline T1-GR & 55 (44 to 65$)$ & $>-0.1719$ & 71.0 (58.1 to 81.8$)$ & 46.0 (33.4 to 59.1$)$ & 17.0 & 0.41 \\
\hline T4-GR & 50 (40 to 61$)$ & $>-0.6860$ & 90.3 (80.1 to 96.4 ) & 17.5 (9.1 to 29.1$)$ & 7.8 & 0.37 \\
\hline CT-GR & 56 (46 to 66$)$ & $<-0.4405$ & 33.9 (22.3 to 47.0$)$ & 79.4 (67.3 to 88.5$)$ & 13.2 & 0.37 \\
\hline LT-GR & 51 (41 to 61 ) & $>-0.1985$ & 58.1 (44.9 to 70.5 ) & 52.4 (39.4 to 65.1$)$ & 10.4 & 0.23 \\
\hline LN-GR & 55 (45 to 65$)$ & $<-0.3620$ & 27.4 (16.9 to 40.2 ) & 87.3 (76.5 to 94.4$)$ & 14.7 & 0.53 \\
\hline CN-GR & 56 (46 to 66$)$ & $>-0.4496$ & 85.3 (73.8 to 93.0$)$ & 28.6 (17.9 to 41.4 ) & 13.8 & 0.46 \\
\hline
\end{tabular}


Table 4

A comparison of ocular thermography to similar tests found in the literature.

\begin{tabular}{llllll}
\hline Authors & Tests & Cutoff values & Sensitivity (\%) & Specificity (\%) & AUC (\%) \\
\hline Current study & T4-5 temperature & $34.7^{\circ} \mathrm{C}$ & 87.1 & 50.8 & 72 \\
& T4-10 temperature & $34.5^{\circ} \mathrm{C}$ & 77.6 & 61.9 & 73 \\
Kim et al., 2015 & Wet BUT & $4.48 \mathrm{~s}$ & 79.0 & 54.8 & 61 \\
& Dry BUT & $3.50 \mathrm{~s}$ & 72.6 & 69.4 & 72 \\
Lemp et al., 2011 & TBUT & $<10 \mathrm{~s}$ & 84.4 & 45.3 & - \\
Yeh et al., 2015 & NIBUT & - & 72.0 & 52.0 & - \\
& TBUT & - & 68.0 & 57.0 & - \\
\hline
\end{tabular}


Fig. 1 The 'diamond' method in marking the ocular surface and OST acquisition. ROI = region of interest.

Fig. 2 ROC curves for static metrics at three different time points. AUC are shown at the legend.

Fig. 3 ROC curves for dynamic metrics at three different attributes. AUC are shown at the legend.

Fig. 4 ROC curves for T4 metrics (static). AUC are shown at the legend.

Fig. 5 ROC curves for T4 metrics (dynamic). AUC are shown at the legend. 


\section{Figure(s)}

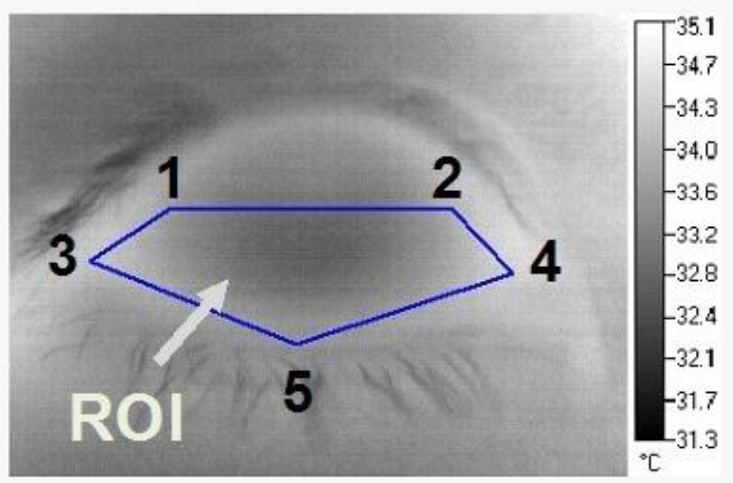

Fig. 1 
at $0 \mathrm{~s}$
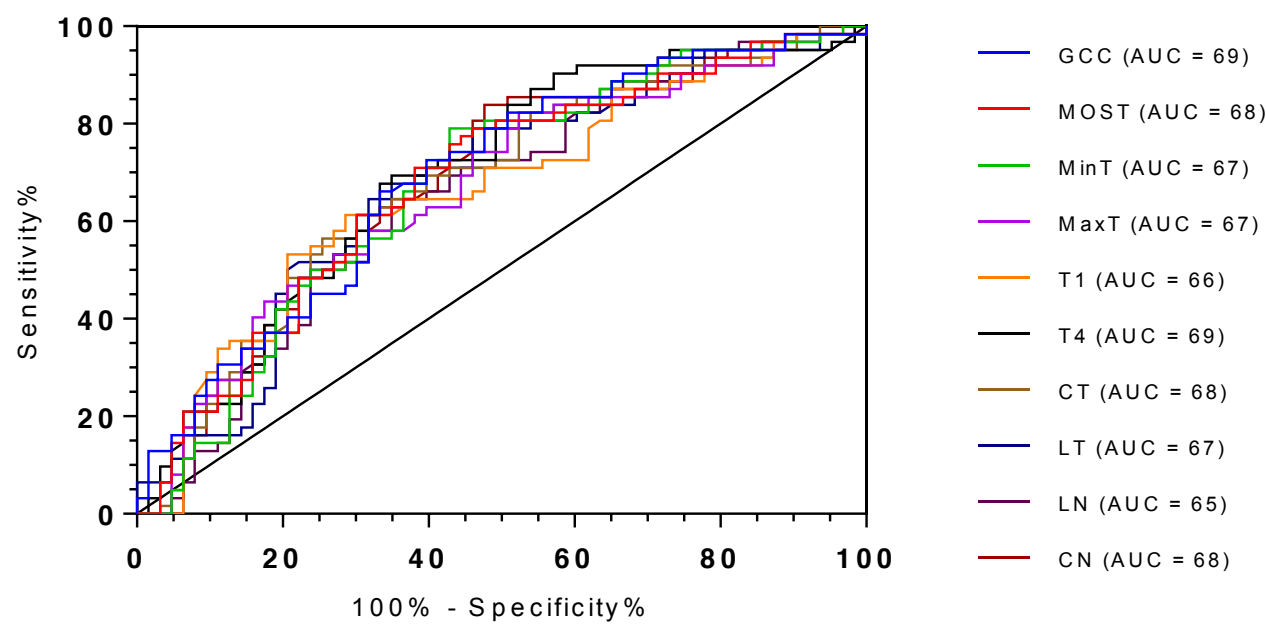

at $5 \mathrm{~s}$
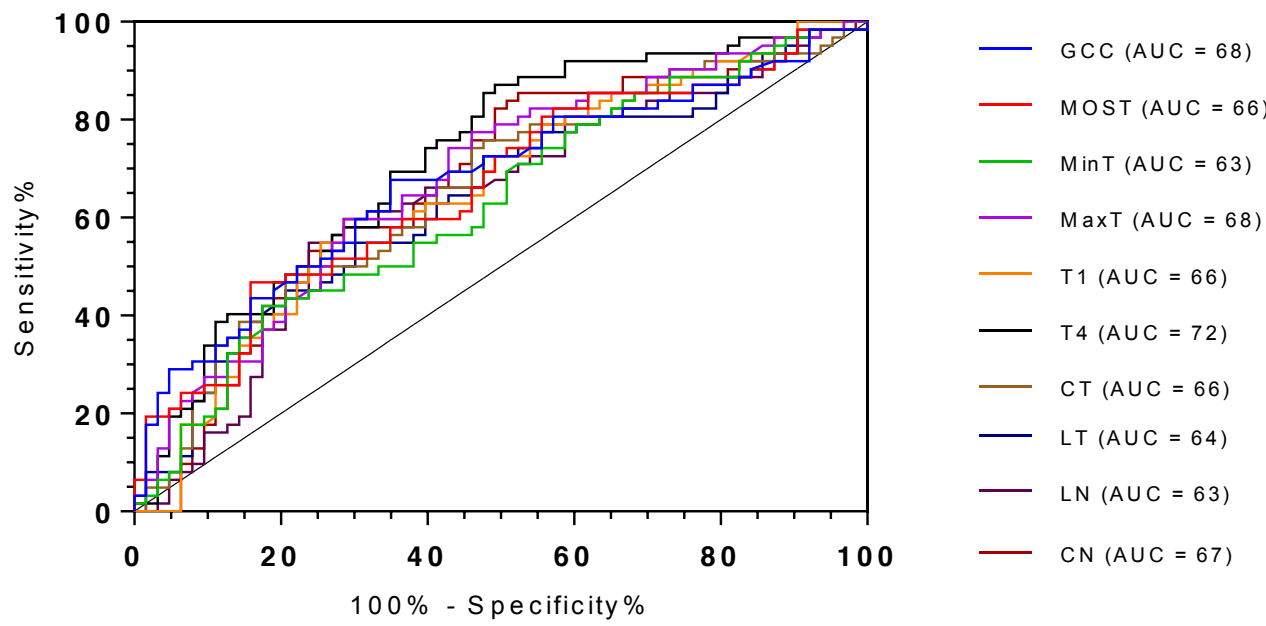

at $10 \mathrm{~s}$

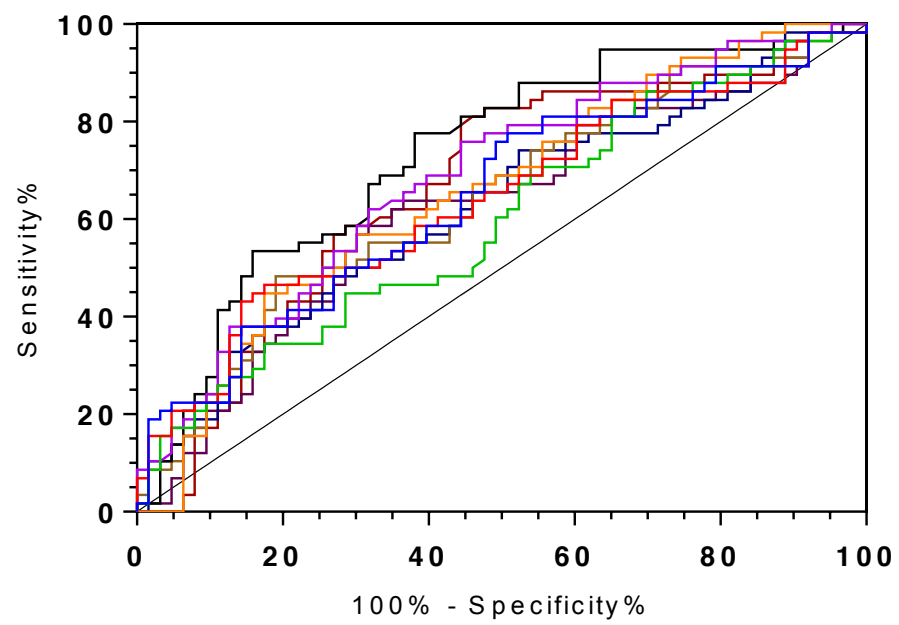

$-\quad \operatorname{GCC}(A \cup C=65)$
$-\operatorname{MOST}(A \cup C=64)$
$-\operatorname{MinT}(A \cup C=60)$
$-\quad \operatorname{MaxT}(A \cup C=69)$
$-\quad \operatorname{T1}(A \cup C=66)$
$-\quad \operatorname{CT}(A \cup C=63)$
$-\quad \operatorname{LT}(A \cup C=62)$
$\quad \operatorname{LN}(A \cup C=62)$
$\quad C N(A \cup C=67)$

Fig. 2 


\section{as y m ptote}
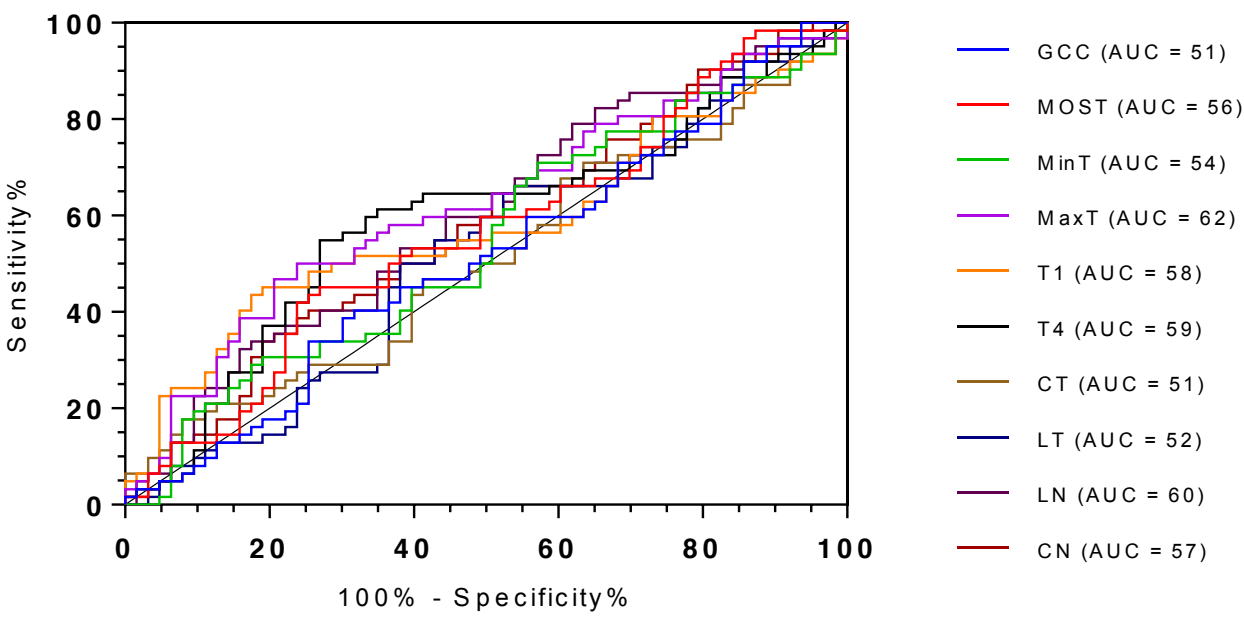

scale
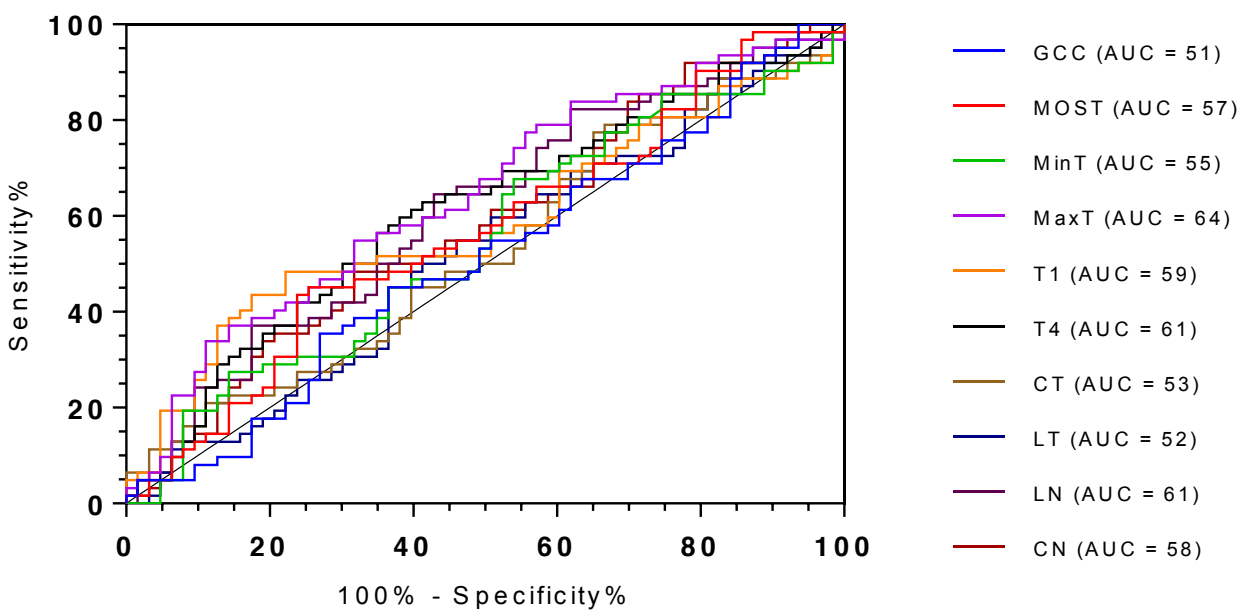

growth rate
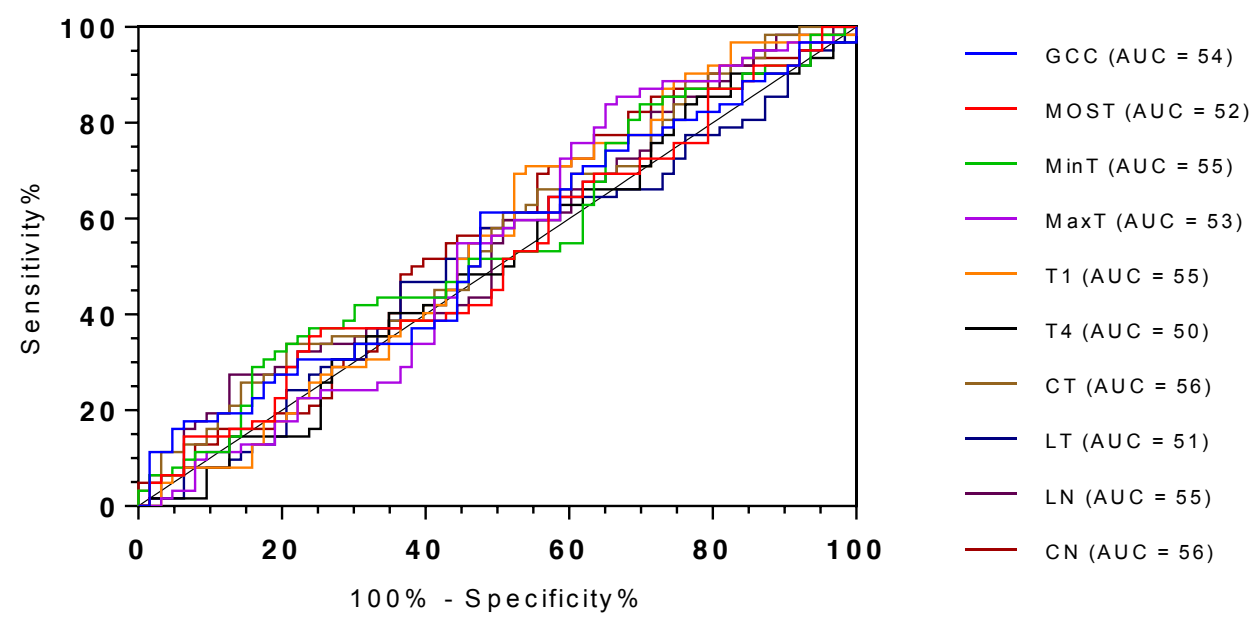

Fig. 3 


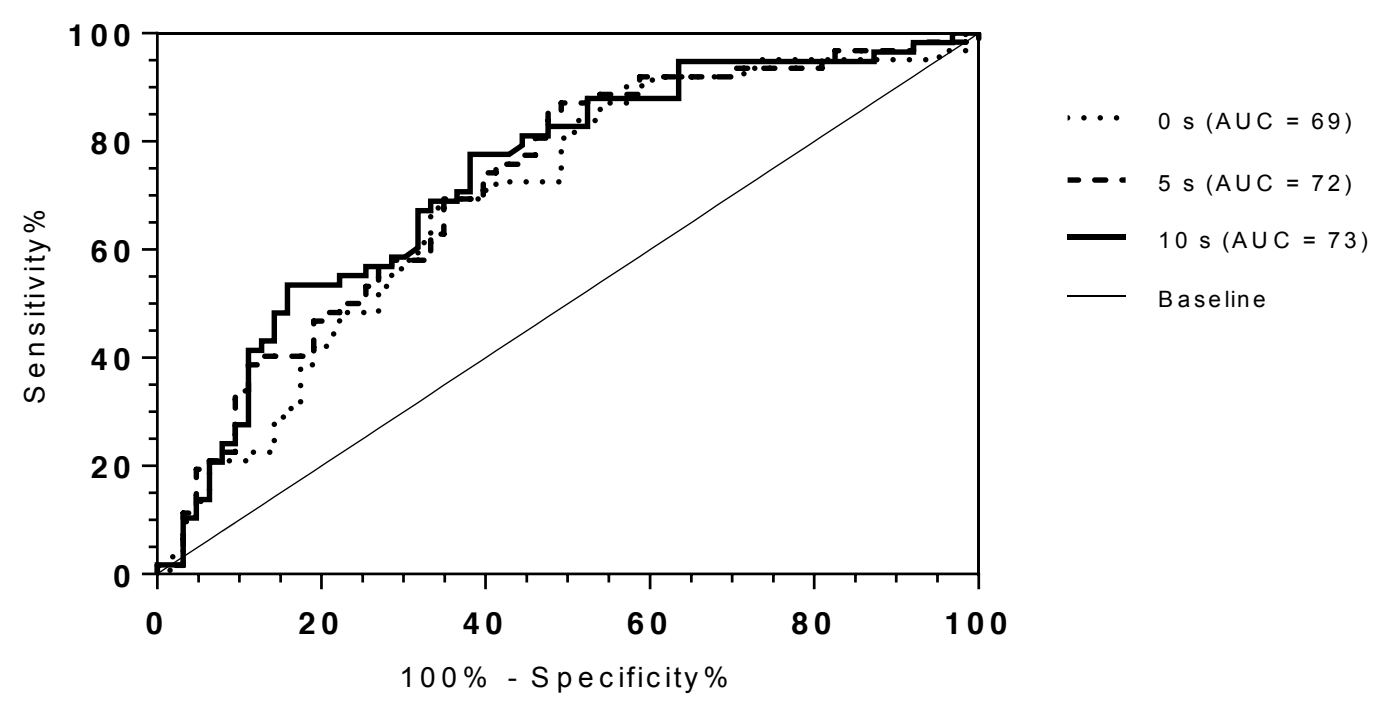

Fig. 4

T4

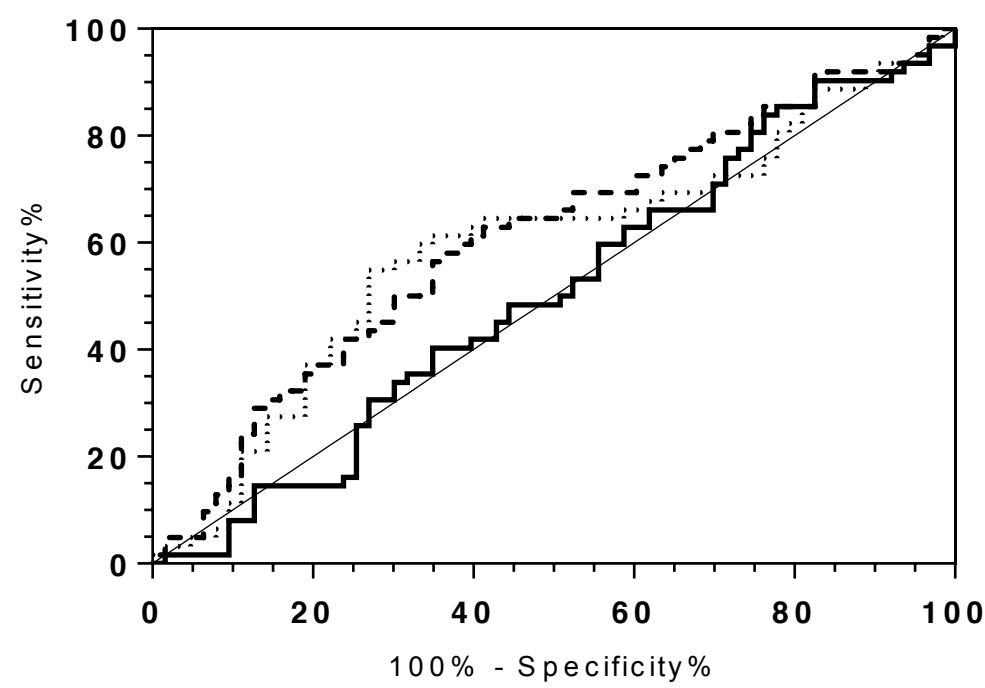

$\cdots \quad$ asymptote $(A \cup C=59)$

- scale $(A \cup C=61)$

Growth rate $(A \cup C=50)$

- B aseline

Fig. 5 